\title{
Response of Chile Pepper to Phytophthora capsici in Relation to Soil Salinity
}

\author{
S. Sanogo, Department of Entomology, Plant Pathology, and Weed Science, New Mexico State University, Las \\ Cruces 88003-0003
}

\begin{abstract}
Sanogo, S. 2004. Response of chile pepper to Phytophthora capsici in relation to soil salinity. Plant Dis. 88:205-209.

The response of chile pepper to salinity and infection by Phytophthora capsici was assessed under greenhouse conditions in plants susceptible or resistant to $P$. capsici. Additionally, the effect of salinity on mycelial growth and production of sporangia and zoospores by $P$. capsici was evaluated in the laboratory. Salinity treatments consisted of varying levels of electrical conductivity (from 1.8 to $14.4 \mathrm{dS} / \mathrm{m}$ ) achieved by amending irrigation water or growth media with a mixture of sodium chloride and calcium chloride. In plants susceptible to $P$. capsici, disease severity increased by approximately 1.3 to 2.7 -fold with increasing salinity level, whereas no such effect was observed in plants resistant to $P$. capsici. Mycelial dry weight increased by 8 to $16 \%$, and radial growth of mycelium was augmented by 5 to $30 \%$ with increase in salinity level. Production of sporangia and zoospore formation were reduced by approximately 3 to 85 and 1 to $93 \%$, respectively, under saline conditions. These results indicate that salinity may predispose susceptible chile pepper plants to infection by $P$. capsici.
\end{abstract}

Additional keywords: Capsicum annuum, Phytophthora root rot

The physical environment in arid and semi-arid regions is typified by several variables that stress crop production. One variable is soil salinity that affects growth and yield of salt-sensitive crops (9). In addition to its direct effects on crops, salinity has been examined in connection with plant infection by a wide array of plant pathogens, including species of Phytophthora $(1,2,5,6,10,13,14)$. Salinity has been reported to increase plant susceptibility and promote Phytophthora root rot of chrysanthemum, citrus, and tomato $(2,5,6,13,14)$.

Soil salinity is a concern in the southwestern United States for furrow-irrigated chile pepper (Capsicum annuum L.; 8), which is a major vegetable crop in New Mexico. In addition, root rot and wilt diseases caused by Phytophthora capsici are a major constraint in chile pepper production. The effect of salinity on infection of chile pepper by $P$. capsici is not known. Understanding the response of chile pepper to salinity and infection by $P$. capsici may provide insight into management of root rot and wilt diseases under conditions of salinity stress.

The objectives of this study were to determine the effects of salinity on (i) growth

Corresponding author: S. Sanogo

E-mail: ssanogo@nmsu.edu

Financial support for this research was provided by the New Mexico Agricultural Experiment Station.

Accepted for publication 26 September 2003.

Publication no. D-2003-1124-04R

(C) 2004 The American Phytopathological Society and reproduction of $P$. capsici and (ii) severity of infection of chile pepper by $P$. capsici.

\section{MATERIALS AND METHODS}

Inoculum preparation. $P$. capsici isolate PWB-24 (3), was used in this study and was grown on V8-juice agar in 9-cmdiameter petri plates in the dark at $25^{\circ} \mathrm{C}$. After 5 days, six mycelial plugs $(1 \mathrm{~cm}$ in diameter) were cut from the culture. The plugs were placed in $20 \mathrm{ml}$ of sterile distilled water in a 9 -cm-diameter petri plate and incubated in the dark at $25^{\circ} \mathrm{C}$ for 3 days to induce sporangia formation. The plates then were transferred to $10^{\circ} \mathrm{C}$ for 60 min, and returned to $25^{\circ} \mathrm{C}$ for $90 \mathrm{~min}$ to trigger the release of zoospores. The content of petri plates then was passed through three layers of cheesecloth to remove agar plugs. The number of zoospores was counted using a hemacytometer, and inoculum concentration was adjusted to $10^{4}$ zoospores $/ \mathrm{ml}$.

Plant production and inoculation. Chile pepper cvs. Joe Parker and Tequilla Sunrise, which are susceptible to $P$. capsici, and resistant chile pepper line Criollo de Morelos \#334 (CM334) were used. Chile pepper seeds were planted in 6-cell plastic trays filled with sterilized TerraLite Metro Mix 360 (W. R. Grace \& Co., Memphis, TN) and maintained in a greenhouse with minimum air temperature ranging from 18 to $20^{\circ} \mathrm{C}$ and maximum air temperature from 29 to $32^{\circ} \mathrm{C}$. At the first fully expanded true-leaf stage, individual seedlings were transplanted into $12-\mathrm{cm}$, round plastic pots filled with sterilized Terra-Lite Metro Mix 360. Seedlings then were fertilized by adding to each pot a 150-ml solution of 20-20-20 (N- $\mathrm{P}_{2} \mathrm{O}_{5^{-}}$ $\mathrm{K}_{2} \mathrm{O}$ ) fertilizer (Peters Fertilizer Products, Fogelsville, PA). When seedlings were at the six- to eight-leaf growth stage, they were inoculated by pouring $25 \mathrm{ml}$ of a zoospore suspension of $P$. capsici $\left(10^{4}\right.$ zoospores $/ \mathrm{ml}$ ) on top of the soilless medium in each pot. Noninoculated control seedlings received $25 \mathrm{ml}$ of sterile water.

Mycelial growth, sporangium formation, and zoospore production by $\boldsymbol{P}$. capsici. Mycelial growth of $P$. capsici under saline conditions was evaluated on $10 \% \mathrm{~V} 8$-juice agar $(100 \mathrm{ml}$ of V8 juice, and $20 \mathrm{~g}$ of agar per liter) and V8-juice medium (100 $\mathrm{ml}$ of $\mathrm{V} 8$ juice per liter) amended with a mixture of sodium chloride and calcium chloride (2:1, molarity: molarity) to generate six salinity treatment levels: 1.8, 4.4, 7.2, 9.5, 11.6, and 14.4 $\mathrm{dS} / \mathrm{m}$. Electrical conductivity was measured using an Accumet AB30 conductivity meter (Fisher Scientific, Pittsburgh, PA). All media were sterilized at $121^{\circ} \mathrm{C}$ after amendment with salt mixture. To evaluate mycelial growth on solid medium, a $1-\mathrm{cm}$ plug of $P$. capsici grown on water agar was placed at the center of a 9-cm-diameter petri plate containing $20 \mathrm{ml}$ of solidified V8-agar medium of each salinity treatment. All plates were placed in a plastic box and incubated in darkness at $25^{\circ} \mathrm{C}$. Colony diameters were measured after 72 $\mathrm{h}$. The experiment was conducted in a completely randomized design with five or six petri plates for each salinity treatment. The entire experiment was repeated three times.

To assess mycelial growth in liquid medium, a $1-\mathrm{cm}$ plug of $P$. capsici grown on water agar was added to a 250-ml Erlenmeyer flask containing $100 \mathrm{ml}$ of V8-juice medium of a given salinity treatment described previously. All flasks were placed on a rotary shaker and incubated at room temperature $\left(23\right.$ to $\left.25^{\circ} \mathrm{C}\right)$ in darkness. After 6 days, mycelial mats were harvested by vacuum filtration of the culture through a double-layer filter paper. The harvested mycelial mats were dried in an oven at $75^{\circ} \mathrm{C}$ for $24 \mathrm{~h}$, and dry weights were recorded. The experiment was conducted in a completely randomized design with three flasks for each salinity treatment. The entire experiment was repeated three times.

Sporangia formation and zoospore production were evaluated using a modified procedure from Rasmussen and Stanghellini (10). A $1-\mathrm{cm}$ plug of $P$. capsici from a 5-day-old culture grown on 10\% V8 agar 
was placed in a petri plate, and $20 \mathrm{ml}$ of nonsalinized water $(0.95 \mathrm{dS} / \mathrm{m})$ or salinized water at each of six salinity levels $(2.7,4.1,6.7,8.6$, and $10.2 \mathrm{dS} / \mathrm{m})$ was added to the plate. Three plates were prepared for each salinity treatment, and plates were incubated at $25^{\circ} \mathrm{C}$. After $48 \mathrm{~h}$, the plugs were observed with a compound microscope at $\times 40$ magnification. Sporangia were counted in five arbitrarily selected views along the periphery of each plug following a clockwise path. Then, the plates were placed at $10^{\circ} \mathrm{C}$ for $45 \mathrm{~min}$, and maintained in an incubator at $25^{\circ} \mathrm{C}$ for 90 min. The solution was filtered through two layers of cheesecloth and $100 \mu$ of acid fuchsin was added. The flask was shaken vigorously, and the number of zoospores per milliliter in the acid fuchsin-treated solution was counted with a hemacytometer. The experiment was conducted in a completely randomized design with three
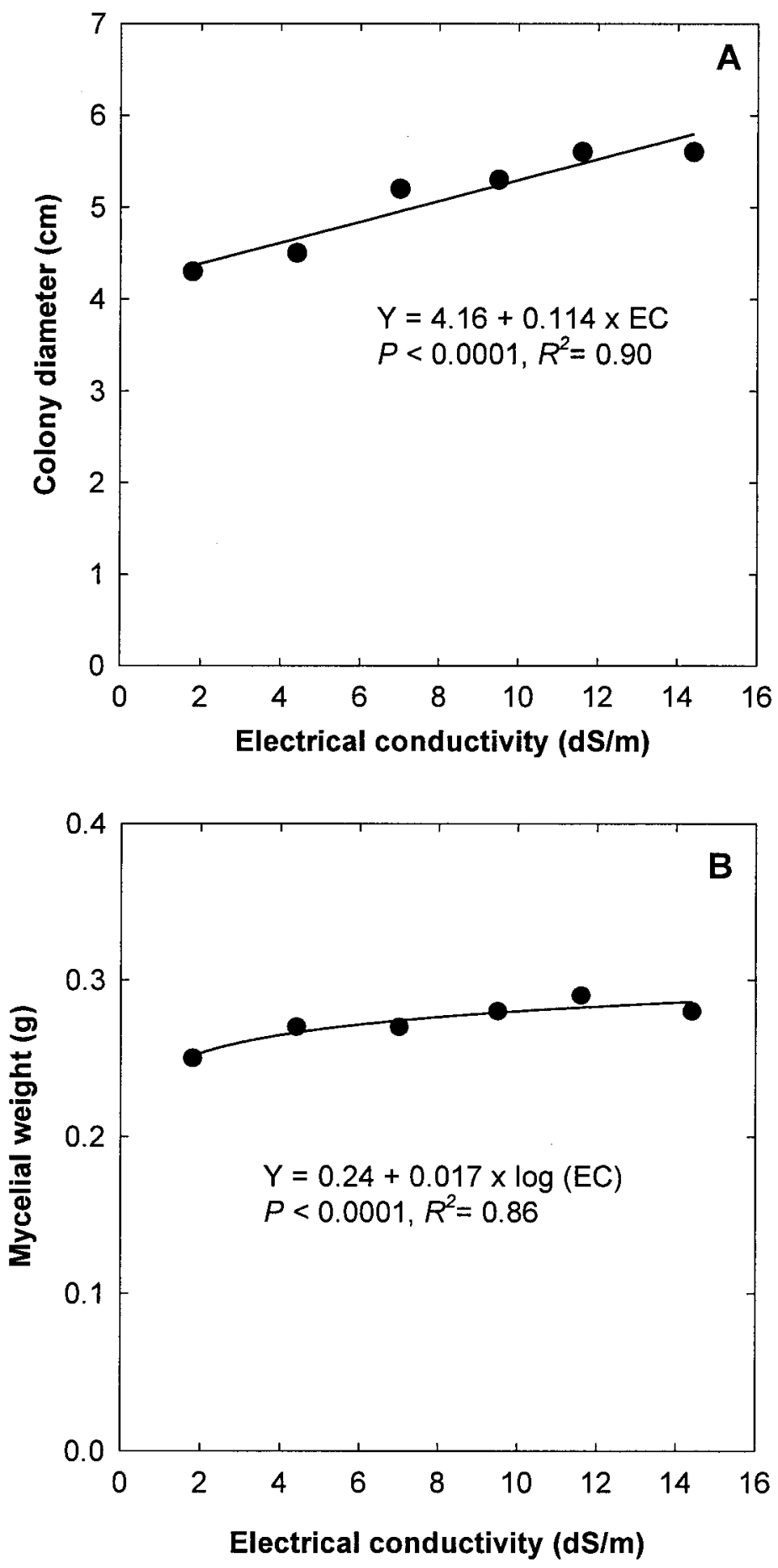

Fig. 1. Relationship between salinity and mycelial growth of Phytophthora capsici on A, V8-juice agar and B, V8-juice media. Salinity levels were generated by amending media with a mixture of sodium chloride and calcium chloride (2:1, molarity:molarity). Each datum point is the mean of three individual experiments.

petri plates for each salinity treatment. Five sporangia and four zoospore counts were taken from each plate. The entire experiment was repeated twice.

Infection of chile pepper by $P$. capsici. Plants (six- to eight-leaf growth stage) were watered daily with $100 \mathrm{ml}$ of nonsalinized water $(0.95 \mathrm{dS} / \mathrm{m})$ or salinized water at each of six salinity levels $(2.7,4.1,6.7$, 8.6, and $10.2 \mathrm{dS} / \mathrm{m}$ ) for 6 days prior to inoculation with $P$. capsici. This quantity of water was adequate to replenish the water level in the soilless medium to container capacity. Salinity level in soilless medium was measured on saturated paste extract, which was prepared by slowly moistening $200 \mathrm{~g}$ of air-dried soilless medium with distilled water and stirring with a plastic spatula until a glistening slurry was obtained, as described by Rhoades et al. (11). The soilless slurry was left to stand for $12 \mathrm{~h}$, then vacuum filtered using a Whatman \#1 filter. The electrical conductivity of the filtrate was measured using an $\mathrm{AB} 30$ conductivity meter.

Inoculation was performed within 30 min after irrigation on the sixth day. Plants noninoculated with $P$. capsici were included in the experiment to provide an assessment of the effect of salinity on plants in the absence of the pathogen. There were 36 treatments consisting of the combination of two cultivars and one line (Joe Parker, Tequilla Sunrise, and CM334), six salinity levels $(0.95,2.7,4.1,6.7,8.6$, and $10.2 \mathrm{dS} / \mathrm{m}$ ), and two inoculum levels (inoculated and noninoculated). Severity of salt injury on aboveground plant parts was rated on a 0 -to- 5 scale as follows: $0=$ no visual symptoms, $1=$ chlorotic and stiff leaves, $2=$ necrotic leaf margins, $3=$ leaf drop, $4=$ wilted, and $5=$ dead. Disease severity on aboveground plant parts was evaluated at 7 days after inoculation using a scale modified from Ristaino (12) as follows: $0=$ no visual disease symptoms, 1 $=$ stem necrosis with no girdling, $2=$ stem necrosis with girdling, $3=$ stem necrosis with $<50 \%$ defoliation, $4=$ stem necrosis with $>50 \%$ defoliation, $5=$ wilted, and $6=$ dead.

The 36 treatments were arranged in a split split-plot design, with inoculum level as whole plot factor, cultivar as subplot factor, and salinity level as sub-subplot factor. Each treatment was replicated six times, with a pot being a replicate. The entire experiment was repeated twice.

Statistical analysis. The response variables measured in this study consisted of the following: (i) growth of mycelium on solid and liquid media; (iii) number of sporangia and zoospores produced; and (iii) salt injury and disease severity. The effect of salinity on these variables was assessed using analysis of variance (ANOVA). Data from each experimental replicate were subjected to ANOVA and error variances were evaluated for homogeneity using procedures outlined by Go- 
mez and Gomez (4). Because there were no significant statistical difference among experiments and the error variances were homogeneous $(P>0.05)$, data from individual experiments were combined.

\section{RESULTS}

Mycelial growth, sporangia formation, and zoospore production. Radial growth of mycelium increased significantly by 5 to $30 \%$ (Fig. 1A) over the range of electrical conductivity examined (1.8, 4.4, 7.2, 9.5, 11.6, and $14.4 \mathrm{dS} / \mathrm{m})$. There was a significant relationship between electrical conductivity (EC) and radial growth $(\mathrm{RG})$ that was best described by the equation $\mathrm{RG}=4.16+0.114 \times \mathrm{EC}$ $\left(P<0.0001, R^{2}=0.90\right)$. A similar result was obtained with mycelial growth in salinized liquid medium (Fig. 1B), and dry weight of mycelium increased by 8 to $16 \%$ over the range of electrical conductivity examined. The relationship between dry weight of mycelium (WM) and EC was best described by the equation $\mathrm{WM}=0.24$ $+0.017 \times \log _{\mathrm{e}}\left(\right.$ EC) $\left(P<0.0001\right.$ and $R^{2}=$ 0.86 ). In contrast to mycelial growth, increasing salinity levels significantly reduced sporangia formation $(P<0.0001)$ and zoospore production $(P<0.002)$ (Fig. $2 \mathrm{~A}$ and $\mathrm{B})$. Production of sporangia was reduced by approximately 3 to $85 \%$ under saline conditions when compared with production level under nonsaline conditions $(0.95 \mathrm{dS} / \mathrm{m})$. Production of zoospores was reduced by approximately $1,23,35,69$, and $93 \%$ at salinity levels of $2.7,4.1,6.7,8.6$, and $10.2 \mathrm{dS} / \mathrm{m}$, respectively, when compared with production level at $0.95 \mathrm{dS} / \mathrm{m}$.

Infection of chile pepper by $\boldsymbol{P}$. capsici. The response of chile pepper to salinity alone consisted of leaf yellowing and stiffness, and necrosis on leaf margins. Salinity injury was more severe on Joe Parker than on Tequilla Sunrise and CM334 (Fig. 3A). Chile pepper cvs. Joe Parker and Tequilla Sunrise displayed disease symptoms within 5 to 7 days of inoculation as girdling or nongirdling stem necrosis accompanied by defoliation or wilting. Analysis of variance indicated that the cultivartreatment interaction $(P<0.0001)$ was significant for disease severity. Most of this significant effect resulted from the fact that chile line CM334 did not display any symptoms compared with cvs. Joe Parker and Tequilla Sunrise. In these two latter cultivars, disease severity increased with increasing salinity level (Fig. 3B). Under saline conditions, disease severity was increased by approximately 1.3- to 2.7fold in Joe Parker and 1.4- to 2.2-fold in Tequilla Sunrise as salinity level increased from 2.7 to $10.2 \mathrm{dS} / \mathrm{m}$. The electrical conductivity values of the saturation paste extracts were $2.3,3.5,6.2,6.6,10.8$, and $12.4 \mathrm{dS} / \mathrm{m}$ when chile plants were irrigated daily for 6 days with $100 \mathrm{ml}$ of water at $0.95,2.7,4.1,6.7,8.6$, and $10.2 \mathrm{dS} / \mathrm{m}$, respectively.

\section{DISCUSSION}

This study has focused on the effect of salinity on growth and reproduction of $P$. capsici, and on the infection of chile pepper by $P$. capsici. The methodological approaches used were similar to those employed by others in assessing the effect of salinity on host plant-pathogen interactions $(5,6,10)$. The results of this study indicate that salinity (i) increases mycelium growth and decreases sporangium formation and zoospore production, (ii) increases disease severity, and (iii) does not change the response of $P$. capsici-resistant plants to infection by $P$. capsici.

Salinity is an important concern in the production of several semi-arid irrigated crops. Tolerance to salinity is variable among crops (8). Chile pepper is considered a salt-sensitive crop and may withstand salinity level of up to $3 \mathrm{dS} / \mathrm{m}$ (7). Salinity of irrigation water and soil in
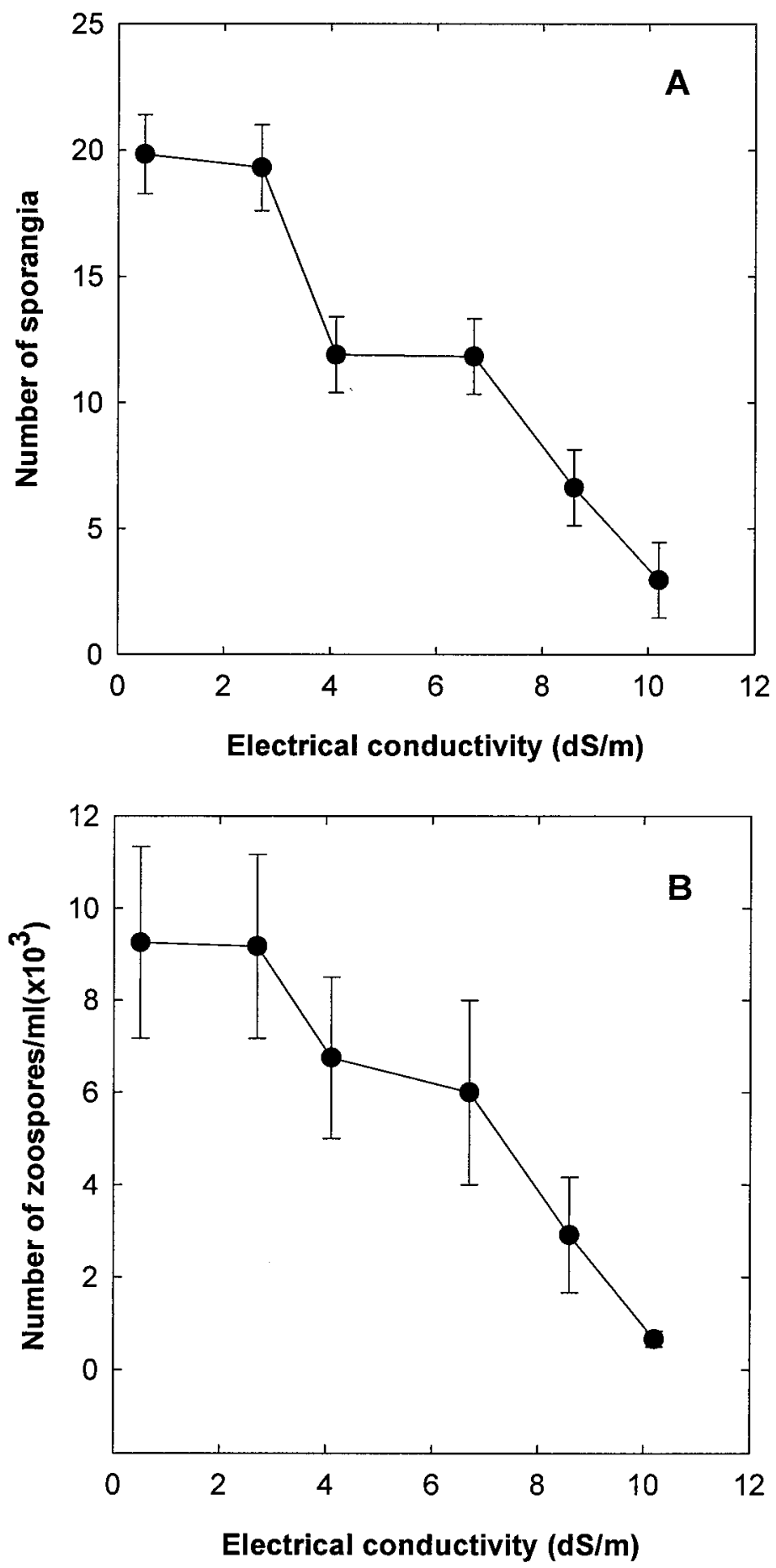

Fig. 2. Production of A, sporangia and $\mathbf{B}$, zoospores by Phytophthora capsici under saline conditions. Salinity levels were generated by amending water with a mixture of sodium chloride and calcium chloride (2:1, molarity:molarity). Each datum point is the mean of two individual experiments. The bar on each point represents the standard error of the mean. Bars with length less than the diameter of the data points are not visible. 
southern New Mexico may range from $<1$ to $>16 \mathrm{dS} / \mathrm{m}$. The levels of salinity used in this study were well within this range.

The effects of salinity on host-pathogen interactions have been studied at various periods over the past three decades, but the effect of salinity on the chile pepper- $P$. capsici pathosystem has not been previously examined. The effect of salinity on $P$. capsici resulted in an increase of mycelial growth and a decrease in production of sporangia and zoospores, and disease severity increased with salinity level. Given the ecological significance of sporangia
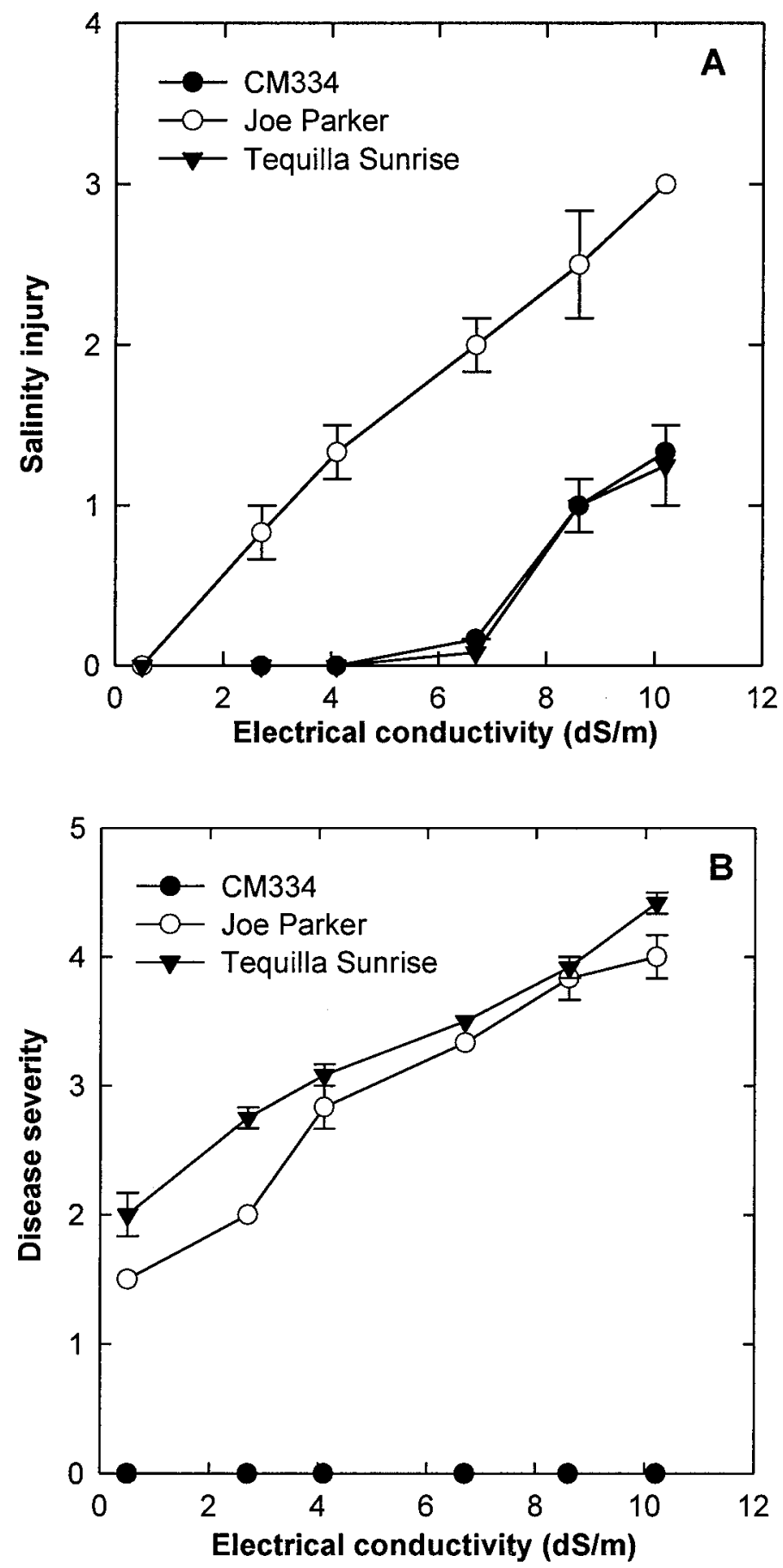

Fig. 3. Severity of A, salinity injury and $\mathbf{B}$, disease symptoms caused by Phytophthora capsici in chile pepper. Chile pepper plants were irrigated daily with water at six salinity levels generated by amending water with a mixture of sodium chloride and calcium chloride (2:1, molarity:molarity). Severity of salt injury on aboveground plant parts was rated using the following scale: $0=$ no visible salt injury symptom, $1=$ chlorotic and stiff leaves, $2=$ necrotic leaf margins, $3=$ leaf drop, $4=$ wilted, and $5=$ dead. Disease severity on aboveground plant parts was evaluated using the following scale: 0 $=$ no visible disease symptoms, $1=$ stem necrosis with no girdling, $2=$ stem necrosis with girdling, 3 $=$ stem necrosis with $<50 \%$ defoliation, $4=$ stem necrosis with $>50 \%$ defoliation, $5=$ wilted, and $6=$ dead. Each datum point is the mean of two individual experiments, with each treatment replicated six times within each experiment. The bar on each point represents the standard error of the mean. Bars with length less than the diameter of the data points are not visible.

and zoospores in the dispersal of $P$. capsici and in plant infection, these results indicate that salinity may predispose chile pepper to plant infection by $P$. capsici. These results are congruent with those obtained by Swiecki and MacDonald (14), who found that soil salinity increased Phytophthora root rot of tomato but reduced asexual reproduction by $P$. parasitica. Similar supporting results have been reported by others $(2,5,6)$.

In a previous study conducted by Votava and Bosland (15), Tequilla Sunrise was reported as a salt-tolerant cultivar, although tolerable salinity levels were not indicated. This cultivar was included in this study to test whether tolerance to salt was related to resistance to disease. Under nonsaline conditions, Tequilla Sunrise was susceptible to $P$. capsici, and disease severity increased with increasing salinity. It appears that the mechanism of salt tolerance active in Tequilla Sunrise did not protect plants from the stresses that enhanced disease.

The $P$. capsici-resistant chile pepper line CM334 maintained resistance to $P$. capsici regardless of salinity level. In contrast, disease severity increased with increasing salinity level in cultivars susceptible to $P$. capsici. This result indicates that the resistance of CM334 to P. capsici was stable in the presence of salinity stress that predisposed the other two cultivars.

This study is relevant to management of $P$. capsici under saline environment in that it provides an understanding of the direct and indirect effects of salinity on P. capsici, chile pepper, and their interaction. In light of the results from this study, an effective management of $P$. capsici in fields with high level of salinity should include, in part, the selection of cultivars with tolerance to salinity and resistance to $P$. capsici.

\section{ACKNOWLEDGMENTS}

I thank S. Thomas and H. Ratnayaka for reviewing this manuscript.

\section{LITERATURE CITED}

1. Blaker, N. S., and MacDonald, J. D. 1985. Effect of soil salinity on the formation of sporangia and zoospores by three isolates of Phytophthora. Phytopathology 75:270-274.

2. Blaker, N. S., and MacDonald, J. D. 1986. The role of salinity in the development of Phytophthora root rot of citrus. Phytopathology 76:970-975.

3. Bosland, P. W., and Lindsey, D. L. 1991. A seedling screen for Phytophthora root rot of pepper, Capsicum annuum. Plant Dis. 75:1048-1050.

4. Gomez, K. A., and Gomez, A. A. 1984. Statistical Procedures for Agricultural Research, 2nd ed. John Wiley \& Sons, Inc., New York.

5. MacDonald, J. D. 1982. Effect of salinity stress on the development of Phytophthora root rot of Chrysanthemum. Phytopathology 72:214-219.

6. MacDonald, J. D. 1984. Salinity effects on the susceptibility of chrysanthemum roots to Phytophthora cryptogea. Phytopathology 74:621624.

7. McWilliams, D. 2003. Soil salinity and sodicity limits efficient plant growth and water use. 
Coop. Ext. Serv. N. M. State Univ. Guide A140.

8. Miyamoto, S., Piela, K., and Petticrew, J. 1986. Seedling mortality of several crops induced by root, stem or leaf exposure to salts. Irrig. Sci. 7:97-106.

9. Navarro, J. M., Garrido, C., Carvajal, M., and Martinez, V. 2002. Yield and fruit quality of pepper plants under sulphate and chloride salinity. J. Hortic. Sci. Biotechnol. 77:52-57.

10. Rasmussen, S. L., and Stanghellini, M. E. 1988. Effect of salinity stress on development of Pythium blight in Agrostis palustris. Phytopathology 78:1495-1497.

11. Rhoades, J. D., Chanduvi, F., and Lesch, S. 1999. Soil salinity assessment methods and interpretation of electrical conductivity measurements. FAO Irrig. Drain. Pap. 57, Rome.

12. Ristaino, J. B. 1990. Intraspecific variation among isolates of Phytophthora capsici from pepper and cucurbit fields in North Carolina. Phytopathology 80:1253-1259.

13. Snapp, S. S., Shennan, C., and van Bruggen, A. H. C. 1991. Effects of salinity on severity of infection by Phytophthora parasitica Dast. ion concentrations and growth of tomato, Ly copersicon esculentum Mill. New Phytol. 119:275-284.

14. Swiecki, T. J., and MacDonald, J. D. 1991. Soil salinity enhances Phytophthora root rot of tomato but hinders asexual reproduction by Phytophthora parasitica. J. Am. Soc. Hortic. Sci. 116:471-477.

15. Votava, E. J., and Bosland, P. W. 2002. Sources of salt tolerance in Capsicum. Capsicum Eggplant Newsl. 21:64-65. 